\title{
Immersive cultural experience through innovative multimedia applications: The History of Monserrate Palace in Sintra (Portugal) presented by Virtual Agents
}

\author{
João Nuno $\mathrm{Neto}^{1}$, Maria João Neto ${ }^{2}$ \\ (1) INOV, IST, UTL, Lisbon, Portugal - joao.neto@ist.utl.pt \\ (2) Art History Institute, UL, Lisbon,Portugal - mjneto@fl.ul.pt
}

KEYWORDS: Cultural Heritage, Monserrate Palace, Multimedia Applications, Multimodal, Embodied Conversational Agents, Multidisciplinary Approach, Immersive and Interactive experience

\begin{abstract}
:
We are currently in the process of making a series of interconnected multimedia applications, in order to value and enliven the monuments of Sintra, Portugal - classified by Unesco as World Heritage site in 1995. This national project, Fala Comigo (Talk2Me), aspires to present new contents, not only to scholars but also to an unlimited number of visitors, and thus achieve a social, cultural, educational and civic mission. As an interdisciplinary project, the historians generate the content, while the engineers and technicians design content-driven multimedia applications. In this phase, our case study is the Monserrate Palace, a revivalist building of the $19^{\text {th }}$ century. These applications profoundly rely on a balance between renewed heritage contents, a rigorous scientific approach and stunning designs. We encounter innovative multimodal ways of visitor-application interaction, mainly with the addition of virtual agents that works as guide assistants with educational purposes.
\end{abstract}

\section{Introduction}

Nowadays, Cultural Heritage has become a vastly discussed subject. It has become a dominant topic in a wide variety of areas, such as numerous systems, applications and serious games, which have been designed while keeping in mind several specific circumstances. Like no other area, Cultural Heritage demands a multidisciplinary organization and effort in order to achieve its crucial goal-user learning.

Without a solid foundation of contents, Cultural Heritage applications are just attractive pieces of software with no real educational use for the visitor. On the other hand, without a coherent and structured scientific approach, the technological systems will not meet the demanding requirements for this type of media. Moreover, if on top of that, we add an absolute necessity for that unique eye-candy factor, we can see the mist forming very quickly. The success of a Cultural Heritage system deeply relies on challenging balance between these three core areas.

To achieve this, there must be a commitment to producing renewed content, developed through with discourses aimed at different age groups and appealing to an awareness of how important it is to preserve artistic heritage. These studies must be presented according to the modern lines of dissemination, based on emerging technologies that capture the attention of these new audiences, establishing a framework that allows for both the dissemination and the enjoyment of heritage.

The creation of Human Computer Interaction (HCI) systems in a Cultural Heritage scenario has been our project's main focus in these past few years. Systems, applications and even serious games have been developed. However, something was clearly missing - a unique connection between the system and the visitor. Since the current results were displeasing, the field of Embodied Conversational Agents and Integrated Dialogue Systems became the solution. Nevertheless, finding new multimodal ways of human- computer interaction, that would amaze any visitor, is demanding. Using the world-renowned game engine Unity $3 \mathrm{D}$, a reusable embodied conversational agent framework to be used in Cultural Heritage scenarios, was created.

Throughout this paper, every decision and action that made possible the creation of a conversational agent based module, which core focus is to interrelate with the user, will be explained.

\section{Monserrate Palace: A brief history}

The Monserrate Palace, inserted in the striking landscape of Sintra, is now the target of an integrated restoration program. After almost half a century in relinquishment, degradation was gradually taking over the historic building.

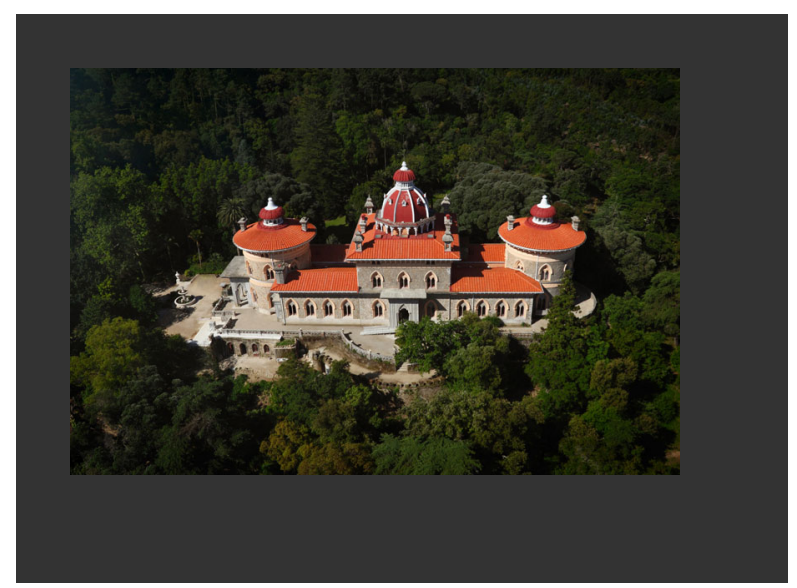


The original construction was due to a wealthy English merchant Gerard Devisme, who in mid-eighteenth century leased the property to the Family Mello e Castro. A few miles from Lisbon, Sintra, with its mild climate, was a much sought-after place by nobles and wealthy burghers for building exquisite and charming summerhouses. Between the sumptuousness of the highlands and the Atlantic Ocean, values such as the picturesque and the sublime of the landscape, attracted the most sensitive spirits in the time of Romanticism. Devisme choose a neo-Gothic program for this country house in Monserrate. Reminiscing a small medieval castle, the cylindrical forms surmounted with merlons flank the longitudinal body of the construction.

Nonetheless, the international notoriety of Monserrate would be attained due to its famous tenant, the writer William Beckford, who inhabited the house between 1794 and 1799. Furthermore, Lord Byron also perpetuates these events in his important poetic work, Childe Harold's Pilgrimage (18121818). Beckford's departure a few years later and the occupation by French's troops, during the Napoleonic wars (1807-1814), left the property abandoned and the house in ruins.

D. Ferdinand of Saxe-Coburg-Gotha-Koháry, a German prince that in 1836 became king of Portugal by marrying the Queen Maria II, deeply desired the property. At Sintra's mountaintop, the King had just started the construction of his own private palace, where a former convent once existed. The idea of extending his dominions was particularly attractive.

However, it was Francis Cook (1817-1901), a wealthy British textile trader, who acquired the property in 1860, after having rented it a few years before. Cook immediately delineates a plan to reformulate the ruined Gothic Revival mansion, turning it in his summer residence. To this end, he hires the architect James Thomas Knowles (1806-1884), who surely received strict orders to respect the pre-existing structure. Knowles creates a decorative interior and exterior, in revivalist-like taste, where Italian and Oriental references abound (Metcalf, 1980). The new palace, suggestively called "Beckford Hill", was reborn with plastic quotes of the Alhambra in Granada, the palaces of Venice and the dome of Florence Cathedral, among others. Francis Cook became an important art collector and, with pieces of great artistic value he decorated not only the house, but also the magnificent gardens in which he had planted with species from different sources.

The property remained in possession of the family for three generations. However the destructive effects caused by World War I in Cook, Son \& Co., led the grandson of Francis Cook to place the property up for sale in 1928. Due to the 1929 's economic crisis, it was not easy to find someone with enough purchasing power to acquire the estate. With the Second World War, the maintenance of the property became unbearable for the Cooks. Francis Ferdinand, grandson of the first Cook, would eventually auction off the precious content of the palace in 1946, selling the property to an individual in the following year.

Although the Portuguese State was presented with this noteworthy possibility, it was decided that Monserrate would not be purchased, even knowing its importance and artistic history, only for acquiring the property two years later. However, the lack of a defined utilization program ran the palace to a progressive deterioration. It was already after the year 2000 that the renovation process began. Primarily with the roofing structure, followed by all main infrastructures, the restoration works have been developed by Parks of Sintra Monte da Lua, the responsible for the management of the monument ever since. These profound contributions awarded PSML with "Best Public Project Renewal" prize in 2010, by Tourism of Portugal. Nowadays, the works take place inside the palace, with the recovery of several rooms - a painstaking process of restoration of the wonderful stucco lining walls and ceilings. Even under the "open for works" policy, those who come to discover the palace are not disappointed. On the contrary, it stimulates a greater flow of visitors, who can actually witness the work process.

\section{Promoting and disseminating cultural heritage through a multimedia experience}

In order to promote the historical and artistic facet of Monserrate Place and the current ongoing rehabilitation campaign, a striving multimedia project was devised.

Furthermore, we envisioned a fresh alternative way of raising the interest of the visitors, by conveying a new, distinctive and enriching experience when learning the history of the monument.

\subsection{A multidisciplinary approach}

Making use of pioneering technologies, a multidisciplinary team composed of art historians, curators, graphic designers and engineers crafted an interactive museology solution committed in renewing the knowledge base of this historic building.

For this proposes, we invested in the artistic and historical research, looking for new contents. After a preliminary phase of content selection, treatment and aggregation with the already known content foundations, it was necessary to consider a unique articulation, which targeted dissemination via attractive multimedia procedures. The requirements differ from those perceived in the presentation of traditional dépliants, or in basic texts for audio guides.

Thus, under the temporal perspective of the monument (in the national and international context), and without losing sight of who were the main actors (owners and artists), it was intended to show the successive steps of the palace: the two major campaigns of works; the architectural and decorative influences, the richness and apparatus of the interiors; the degradation that ensued when the palace was unoccupied, and ultimately, the restoration as a work in progress, looking to show how the work of art is fragile and the importance of conservation.

With the themes defined and assigned with suggestive names for the multimedia systems, it was necessary to determine the technical solutions that best served the educational purposes of each one. This was an interesting combination of ideas among historians and technicians in order to maximize results for the creation of a high quality cultural product. 


\subsection{Immersion and Interaction}

The use of three-dimensional representations presents itself as an excellent visual translation of bi-dimensional images, such as architectural drawings. These 3D representations are much more enlightening to the general public. Their reading and understanding are immediate, serving as a framework for other iconographic sources, such as prints, drawings or photographs. While spaces were recreated, it also presented the possibility of inserting historical characters.

The introduction of embodied conversational agents harvests a particular empathy in the public, since they provide the necessary link for achieving the main goal with this type of creation, which is promoting maximum interaction by establishing a spoken dialogue where the agent answers the visitor's questions in real time. Thus, together with the immersive experience, the visitor is encouraged to interact, acquiring an active assertiveness that favors the assimilation of knowledge.

In the field of immersion and interaction, serious games have been taking an active role in the dissemination of cultural heritage (Anderson, Mcloughlin, Liarokapis, Peters, Panagiotis, De Freitas, 2010) (Neto, Silva, Neto, Pereira, Fernandes, 2011). They are an excellent way of transmitting knowledge through playing. This mechanism operates in information transferring, taking on a specific didactic form that presents very positive results. Also, with the motivation generated by a game, the user takes a significant commitment that is unparalleled in a multimedia application only with informative purposes. Given these characteristics, our set of complementary multimedia applications and serious games follow these principles.

\subsection{Design and usability for visitor's engagement}

The success of these applications profoundly relies in the combination of three dissimilar factors: an attractive and striking design, impressing the visitor and enhancing the cultural experience; a defined pedagogic orientation, correctly steering the user throughout the learning process; and innovative multimodal ways of human-computer interaction, increasing user immersion and engagement (Zyda, 2005).

A spot-on combination and balance between these core factors is decisive for a correct user engagement. Plus, an ideal hardware support choice is tremendously important as well, since the chosen supports need to accommodate all the features offered by the applications. Some applications may demand large multi-touch screens since they were thought for a wider crowd interaction, when others may only require smaller screens, as they were considered for single-user engagement.

The mobile solution is ambivalent. It serves the objectives for those who like to use their own device, even when other fixed supports are available. Additionally, in museums and monuments where the number of simultaneous visitors can be so high that kiosks are not a sensible option, the mobile presents itself as the ideal solution.

Lastly, due to increasingly smaller budgets in this area, the multimedia applications need to answer a series of basic requirements. Besides the topics already mentioned, we had to take into account fundamental questions of how these applications might be quickly reused, modified and corrected. Thus, it is intended that if required, the monuments' managers can quickly make updates and those who design and architect the systems can reuse their work in other contexts.

Therefore, these projects were designed to be stimulating, challenging the user constantly, while never disregarding the important cultural and educational aspect.

\section{Monserrate's Applications: Type, Themes and Technical Solutions}

Following the principles described in the previous section, we created a complete historical set of seven multimedia applications. Enhancing content accessibility allows for the most fundamental objective of a Cultural Heritage application - user learning. By using complementary cultural contents, we designed simple yet memorable interfaces, where the contents are well conveyed and absorbed.

These applications are grouped by three distinctive types: Multi-touch Informative, Multi-touch Interactive and Serious games (table 1).

\subsection{Multi-touch Informative Applications}

Looking to the first type - Multi-touch Informative Applications - we have two main themes. Firstly, the Lords of Monserrate, which is dedicated to the different owners of the palace estate throughout the centuries. Here, we had to take into account the diverse genealogical aspects of all the lords and nobleman that inhabited Monserrate. The volume of information demanded a coherent approach and a strong inter-relation of all the elements, leading to the creation of a cultural-content network. Moreover, the information about one individual is connected with the other applications. Using content-based steering, the visitor seamlessly crosses through all the elements that concern a specific individual.

As for the other Informative app, The Restoration, ilustrates the evolution of the degradation phase and the following recovery process, through a mobile augmented reality (AR) application. This solution presented itself as the most promising to effectively show the visitor the declination and all the steps towards full restoration. As each room of the palace has a distinct covering plaster with a specific decorative pattern, these are used as the AR image-target. An image-target is a specific pre-assigned pattern that, when recognized by the mobile device camera, triggers an action. Thus, the camera is able to identify each plaster design and therefore acknowledge the room that the visitor is in. This generates specific information and images about that room and its restoration process on the mobile phone.

\subsection{Multi-touch Interactive Applications}

Regarding the second type - Multi-touch Interactive Applications - the motto was to promote the visitors' discovering process. With Monserrate: Two Palaces, the visitor will be able to interact with the different architectural 
solutions. For this purpose, we used two distinct 3D models. The first model, created in 3DStudioMax, was made using architectural drawings of the primitive construction dated to the $18^{\text {th }}$ century. The actual palace model resulted from a laser-scanning procedure done by the Portuguese company ArtScan, with some further simplifications to be gameengine-ready (Neto, Neto, Silva, 2011).

For the treatment of the interiors - At the time of Cook Family, we used a magnificent collection of old photographs taken when the Cook family lived in the Palace. These are hidden beneath current pictures of each room, and user is invited to discover them through an image discovery swipe procedure. The revelation is exciting, enabling the visitor to realize how the palace was richly decorated with works of art of considerable value.

The beauty of the landscape and architecture of Monserrate always attracted painters, designers, photographers and filmmakers. Displaying this iconographic wealth to the visitor is the purpose of Monserrate through Images, where the four-finger touch procedures (the user can pitch, swipe, zoom in and out) enhance the appreciation of the detail of each image.

\subsection{Serious Games}

Finally, in the Serious Game type section two distinctive games were created. First, What you know about Monserrate?, a quiz-based game, where the visitor tests the knowledge acquired throughout the exhibit. A virtual agent presents a short promotional video with all the fundamental cultural information, asking the visitor four questions afterwards. This interactive dialogue is an engaging way of accessing if the informational was correctly conveyed.

Lastly, we are currently producing an immersive serious game with a complex plot, were the usage of embodied conversational agents establishes new boundaries. Based on the story of the palace, the fictional plot centres on a group of precious works of art purchased by Cook, and which have now disappeared without a trace. The aim is for players to find out where these pieces have been hidden in the palace gardens. Players subtly receive cultural information and success depends on the amount of knowledge learnt about the history of the monument.

All these applications have, as common denominator, multimodal ways of interaction. As the visitor interacts with the multimedia contents of the applications, they can also interact with the conversational agent. Merging these two concepts can improve the global visiting experience and play an important role in the learning process. When interacting, the visitor can use a multi-touch based input or simple and intuitive voice commands. In particular scenarios, the ECA can help and guide through, always ready to respond to current-domain questions that may surface. In parallel, it is possible to offer an innovative experience where the ECA's knowledge domain changes according to the specific application scene. Handling the various core features, as for example the facial and body animations, complex behaviour and personality and the real-time interactive dialogue are the results of a complex and on-going research process. We had to design, architect, and produce a set of various tools to be able to explore the use of virtual agents in multimedia applications for Cultural Heritage.

\section{Using Embodied Conversational Agents ECAs}

When approaching this problem it was necessary to take into account our founding requirements, capacities, objectives and the preceding works done in this area of knowledge. The Cultural Heritage paradigm fairly differs from the usual scenarios where Embodied Conversational Agents are commonly used. However, the better way to convey cultural and educational knowledge to the visitor is to use a humanlike historical character, equipped with the complete vital informational of a heritage site.

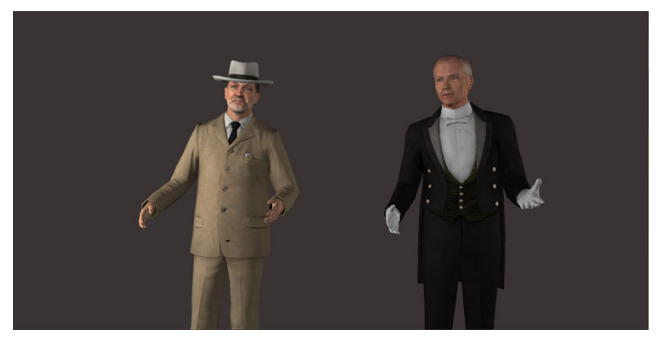

Figure 2. Historical virtual characters

As mentioned before, this information has to be previously aggregated and restructured to be usable in a pioneering multimedia setup. Without specifically crafted cultural contents and proper virtual agent usage, the cultural heritage message will not be passed correctly. As we can see, there are many challenges to overcome in order to successfully provide a new and immersive experience to the visitor.

Although a virtual agent plays a decisive role in this multimedia scenario, the users' discovering process must also be somewhat independent. The visitor needs to interact freely, while knowing that the agent is always there to support them, even when it is not visible.

Following these concepts, we defined a structured approach to explore the benefits of using a virtual agent in a multimedia application for Cultural Heritage:

- Non-interactive animation sequences must be brief and clear to engage the visitors.

This is the case of most opening scenes where, typically, the user knows slight or nothing about the topic in hand. The agent must be efficient on conveying the primary cultural contents, trying to raise the interest of the visitor swiftly. If the visitor is not defied, the probabilities of abandoning the application are awfully high. This is the most critical stage of the interaction.

- The Embodied Conversational Agent model and animations must be realistic enough.

When engaging the virtual agent in a conversation, the user should be confortable and captivated. Only with realism can a user immersion in a real-time conversation be accomplished. If the animations are poorly made or the agent's 3D model has no quality, the interaction will not have the same followthrough effect that it should. A great animation library to mimic numerous human movements in a convincing way was a key requirement. This process grasps three main cores: 
face movements, full-body animations and complex human emotions. Without appropriately developing these three features, real-time interaction will be a poorer experience for the visitor. By adding the Question \& Answer component and the Behavioural module, it is possible to create Agents with a specific personality. However, that personality is only believable if all parts involved work accordingly, mainly the emotions and body animations.

\section{- The Embodied Conversational Agent must be context-aware at all times}

The last important thing to attend is the agent's knowledge base, already mentioned in the previous topic. Instead of creating a global Question \& Answer system, which is a valid option but only in restrict domains, it is far more effective to design several dissimilar QA modules, to serve each section of the application. By doing this, the ECA can straightforwardly access and retrieve the correct answer more efficiently. Otherwise, the system would probably overload when trying to obtain the answer in a larger knowledge base.

Moreover, this bears another positive consequence: by separating the modules, the navigational system is profoundly altered. This means that it is easier to go from one application to the other, without the hassle of going back and repeating content. Therefore, every application scene has a specific context locally and globally. As the visitor may pass from one application to another, the virtual agent must know, at all times, what the visitor has seen before to proper explain the cultural contents presented in that current scene.

\section{An innovative HCI system}

Facing the challenges described in the preceding section, we had to come up with an innovative Human Computer Interaction (HCI) system built in a modular approach specifically designed to assist the visitor in the course of a Cultural Heritage exhibit. In order to achieve this ambition, we developed an Embodied Conversational Agent Framework - ECA Framework.

This framework allows the creation, configuration and usage of virtual agents throughout various kinds of multimedia applications. Based on a spoken dialogue system, an Automatic Speech Recognition (ASR), Text-to-Speech (TTS) engines, a Language Interpretation, VHML Processing, Question \& Answer and Behavior modules are used. These essential features have very different roles in the global virtual agent framework procedure, but they all work together to accomplish realistic facial and body animations, as well as complex behavior and disposition.

The ASR engine - Audimus (Meinedo, Caseiro, Neto, Trancoso, 2003): - is responsible for the multimodality of interaction that we endowed the system with. This engine actively collects all the voice-input commands of the visitor.

The TTS engine - Dixi (Paulo, Oliveira, 2002) - generates an audio file with phonetic and temporal tags. The phonetic tags are transformed into visemes, which are used to generate the agent's facial animations, allowing a proper and realistic form of communication between the agent and the visitor. to analyze and process it in order to produce a valid followthrough action. We created a Language Interpretation module formed by several natural language processing techniques to do exactly that.

Furthermore, we have a Question \& Answer module(Neto, Cassaca, Viveiros, Mourao, 2006) functioning as a domain knowledge datacenter. Stored here is every question and possible answer in agent's sphere of expertise.

The behavior module regulates and generates the personality and major traits of the ECA. Our future work will focus on perfecting this module, turning it into a more dynamic process.

For standardization and reuse purposes, Virtual Human Markup Language (VMHL) is used to create the animation timeline for the ECA.

Finally the game engine Unity3D, where the input is received and the output rendered, visually supports the system. With this base architecture, we can achieve real time interaction, extensive cultural domain knowledge and easy dialogue usability.

\section{Conclusions}

In conclusion, it is necessary to highlight the current high demand for promoting Cultural Heritage. There is a firm belief that for a proper and attractive transfer of cultural information, the development of multimedia applications that heavily rely on realistic Embodied Conversational Agents is mandatory. This is an on-going research project, since in the past the delivery of the cultural message was compromised due to poor design and simplistic agents.

Therefore, the goal is to design thoroughly structured applications that are able to capture the visitor's attention, by the pleasing aesthetics of the application's design and the excitement generated by a multi-modal interaction with the Agent, whether by spoken language or multi-touch interfaces.

Even though the work is currently in an experimental phase, the multimedia applications of the Monserrate Palace already register an important impact among the public. Since the palace lost its entire artistic endowment, the applications constitute a new attraction and a source of entertainment for the visitors. The games are the most utilized applications, mostly by more than one person at the same time.

These interfaces create an immersive experience for the users, in different themes under specific historical settings, conveying cultural programs planned under a new didactic and technological perspective.

Acknowledgments This research has been partially funded by Project FALACOMIGO: Project in co-promotion in the ambit of QREN, finance by EU/FEDER through COMPETE, $\mathrm{n}^{\circ}$ 13449. Global investment of 1.304.982,01€ with a non-refundable incentive of $926.333,97 €$, executing from 3-5-2010 to 31-10-2012.
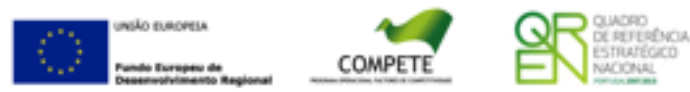


\section{References}

Anderson, E., Mcloughlin, L., Liarokapis, F., Peters, F., Panagiotis, P., De Freitas, S.: Serious Games in Cultural Heritage - State-of-the-Art Report, published in the 10th International Symposium on Virtual Reality, Archaeology and Cultural Heritage VAST - State of the Art Reports (2009)

Meinedo, H., Caseiro, D., Neto, J., Trancoso, I.: Audimus a broadcast news speech recognition system for the european portuguese language. In: Computational Processing of the Portuguese Language, ser. Lecture Notes in Computer Science, N. Mamede, I. Trancoso, J. Baptista, and M. das Gracas Volpe Nunes, Eds. Springer Berlin / Heidelberg, 2003, vol. 2721, pp. 196-196.

Metcalf, P.: James Knowles Victorian Editor and Architect. Clarendon Press, Oxford (1980)

Neto, J. P., Cassaca, R., Viveiros, M., Mourao, M.: Design of a multimodal input interface for a dialogue system, In:
PROPOR, 2006, pp. 170-179.

Neto, J., Neto, M., Silva, R.: Historic buildings through a multimedia experience. A research project on the palaces in Sintra (Portugal). In: Virtual Palaces I. Digitizing and Modeling Palaces. Proceedings of the European Science Foundation Research Networking Programme PALATIUM Meeting at Leuven, 18-19 November 2011.

Neto, J.N., Silva, R., Neto, J.P., Pereira, J.M., Fernandes, J.: Solis'Curse - A Cultural Heritage Game Using Voice Interaction with a Virtual Agent. vs-games, pp.164-167, 2011

Paulo, S, Oliveira, L. C. Multilevel annotation of speech signals using weighted finite state transducers. 2002 Third International Conference on Games and Virtual Worlds for Serious Applications, 2011

Zyda, M.:From visual simulation to virtual reality to games. IEEE Computer 38, 9 (2005), 25-32.

\section{Appendix}

\begin{tabular}{|c|c|c|c|c|}
\hline Application Name & Type & Themes & Main Technical Solutions & $\begin{array}{c}\text { Hardware } \\
\text { Support }\end{array}$ \\
\hline $\begin{array}{c}\text { Lords of Monserrate } \\
\text { Monserrate: Two Palaces }\end{array}$ & $\begin{array}{l}\text { Multi-touch Informative } \\
\text { Multi-touch Interactive }\end{array}$ & $\begin{array}{c}\text { Owners over time } \\
\text { Evolution of architectural } \\
\text { solutions }\end{array}$ & $\begin{array}{l}\text { Cultural content network } \\
\text { 3D model interaction }\end{array}$ & $\begin{array}{c}\text { Multi-touch } \\
\text { kiosk } \\
\text { Multi-touch table }\end{array}$ \\
\hline $\begin{array}{l}\text { At the time of Cook Family } \\
\text { Monserrate through Images }\end{array}$ & $\begin{array}{l}\text { Multi-touch Interactive } \\
\text { Multi-touch Interactive }\end{array}$ & $\begin{array}{l}\text { Interior decoration of the } \\
\text { palace } \\
\text { Monserrate revisited by } \\
\text { artists } \\
\end{array}$ & $\begin{array}{c}\text { Image discovery swipe } \\
\text { Multi-touch image interaction }\end{array}$ & $\begin{array}{c}\text { Multi-touch } \\
\text { kiosk } \\
\text { Multi-touch table }\end{array}$ \\
\hline $\begin{array}{c}\text { The Restoration } \\
\text { What you know about } \\
\text { Monserrate? }\end{array}$ & $\begin{array}{l}\text { Multi-touch Informative } \\
\text { Game - Quiz }\end{array}$ & $\begin{array}{c}\text { Degradation and recovery } \\
\text { General History of } \\
\text { Monserrate }\end{array}$ & $\begin{array}{l}\text { Augmented Reality } \\
\text { Interactive Dialogue }\end{array}$ & $\begin{array}{l}\text { Mobile devices } \\
\text { Multi-touch } \\
\text { kiosk } \\
\end{array}$ \\
\hline The Treasure of Monserrate & Immersive Game & $\begin{array}{c}\text { General History of } \\
\text { Monserrate and his owners }\end{array}$ & Context sensitive storyline & $\begin{array}{l}\text { Multi-touch } \\
\text { kiosk }\end{array}$ \\
\hline
\end{tabular}

Table 1. Multimedia Applications for Monserrate Palace - Connection between historical themes, technical solutions and support hardware. 